
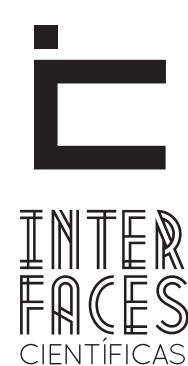

HUMANAS E SOCIAIS

\title{
RELIGIOSIDADE AFRICANA NO TRATO DO SOFRIMENTO PSÍQUICO: CONTRIBUIÇÕES PARA UMA PSICOLOGIA AFROCENTRADA NO BRASIL
}

\section{RELIGIOSIDAD AFRICANA EN EL TRATAMIENTO DEL TRASTORNO PSÍQUICO: CONTRIBUCIONES A UNA PSICOLOGÍA AFROCENTRADA EN BRASIL AFRICAN RELIGIOSITY IN THE TREATMENT OF PSYCHOLOGICAL DISTRESS: CONTRIBUTIONS FOR AFROCENTRED PSYCHOLOGY IN BRAZIL}

\section{RESUMO}

As práticas de Religiosidade de matriz africana promovem prováveis contribuições para elaboração de uma possível Psicologia afrocentrada no Brasil, configurando lugar de investigação sobre como o sentimento de religiosidade afrocentrado contribui com o trato do sofrimento psíquico decorrentes da escravização do povo negro e imposição eurocêntrica sobre afrodescendentes até os dias atuais. Essas contribuições servem de material para estudos e investigações que ajudem na elaboração de uma Psicologia Afrocentrada em contraponto a Psicologia eurocentrada já existente. Objetivo geral, investigar como manifestações de religiosidade africana se constituem enquanto trato do sofrimento psíquico. Será utilizado o método lógico-dedutivo, a partir de revisão, leitura, análise e seleção de fontes bibliográficas voltadas ao tema proposto. Serão considerados os critérios de tempo, idioma, metodologia e relação direta com o tema.

\section{PALAVRAS-CHAVE}

Religiosidade Africana. Sofrimento Psíquico. Psicologia. 


\section{ABSTRACT}

Those with African roots Religiosity practices promote probable contributions to the preparation of a possible afrocentred Psychology in Brazil, setting place of research on the sense of afrocentred religiosity contributes to the treatment of psychological distress resulting from the enslavement of black people and Eurocentric imposition of African descent to the present day. These contributions serve as material for studies and research that will help in developing a Afrocentred Psychology as opposed eurocentred psychology existing one. General objective, investigating how African religious manifestations constitute tract while psychological distress. It will use the logical-deductive method, from review, reading, analysis and selection of literature sources focused on the theme. They will be considered the time criteria, language, methodology and directly related to the theme.

\section{KEYWORDS}

African Religiosity. Psychological Distress. Psychology.

\section{RESUMEN}

Las prácticas de religiosidad de origen africano promueven probables contribuciones para elaboración de una posible Psicología afrocentrada en Brasil, configurando lugar de investigación sobre como el sentimiento afrocentrado contribuye con el tratamiento del trastorno psíquico engendrado de la esclavización del pueblo negro e imposición eurocéntrica sobre afrodescendientes hasta los días actuales. Esas contribuciones sirven de material para estudios e investigaciones que ayuden en el desarrollo de una Psicología afrocentrada en contraposición a la Psicología eurocentrada, ya existente. El objetivo general es investigar como manifestaciones de religiosidad africana se constituyen con la función de tratamiento de trastorno psíquico. Se utilizará el método lógico-deductivo, a partir de revisión, lectura, análisis y selección de fuentes bibliográficas que se centran en el tema propuesto. Serán considerados los criterios de tiempo, lengua, metodología y relación directa con el tema.

\section{PALABRAS CLAVE}

Religiosidad Africana. Trastorno Psíquico. Psicología. 


\section{INTRODUÇ̄̃̃O}

Inúmeras são as religiões e suas contribuições para a saúde do ser humano. Em vista disso, a diversidade de saberes e fazeres das religiões de matriz afrocêntrica, numa interface com a Psicologia, faz emergir a possibilidade de uma Psicologia Afrocentrada, Nascimento (2009) atenta ao sofrimento psíquico devido à escravidão e desafricanização, negação da africanidade, condições impostas pelo colonizador europeu sobre o povo escravizado em suas colônias.

Fora da África, esse povo, teve seus corpos nus como oráculo, como forma de resguardar a identidade e a memória de sua tradição e cultura, mistérios passados por meio da oralidade. Com o aprendizado adquirido, articulado à vivência, a oralidade é considerada pelos yorubás como superior; apesar dos mesmos reconhecerem o valor da cultura letrada do colonizador, esclarece Sodré (1988, APUD CASTILLO, 2010, p. 29).

Num processo de submissão, embranquecimento e busca de sobrevivência e resistência, esse mesmo povo teve sua religião e religiosidade milenares, usurpadas e deformadas, produzindo nos sujeitos e seus descendentes uma abstinência de sua cultura, de sua identidade; ou seja, a sua forma original de viver. Religiosidade e espiritualidade seriam dimensões mais amplas e mais independentes de denominações e formas institucionalizadas específicas de religião (DALGALARRONDO, 2008, p. 23), no caso dos escravizados essas dimensões atuaram em contexto hostil, numa profunda realidade e sensação de não pertencimento, de vazio, de inadequação, de solidão, tudo isso resultando em sofrimento psíquico.

Este trabalho tem como tema Religiosidade africana no trato do sofrimento psíquico. 0 proposto é uma reflexão sobre fé, espiritualidade e religiosidade, elementos que estão imbricados e distintamente dissociados historicamente. Esses elementos, a partir do sujeito, são tomados como distintos para alívio de seu sofrimento, seja este tanto do físico quanto da alma, promovendo assim sensação de acolhimento, conforto, acalento, satisfação em diversos momentos da vida do mesmo. Bem como, quando esses elementos são exacerbados, tornam-se motivo para manifestações de fanatismo ou conflitos entre inúmeros sujeitos e comunidades, adeptos ou não a alguma manifestação de religiosidade.

Sem intenção de esgotar o tema, Religiosidade africana e sofrimento psíquico, justifica-se a escolha do mesmo, por identificar a existência de manifestações e práticas de religiosidade de matriz africana com fins terapêuticos, que se ocupam com a saúde do sujeito, visando a promoção de alívio do sofrimento psíquico, na perspectiva da saúde mental.

Nessa dimensão, a psicologia, por estudar a psique a partir do comportamento humano, em suas diversas manifestações, pode observar na cultura africana, um trato peculiar das demandas trazidas por adeptos ou simpatizantes de religiosidade afrocentradas ancestrais. Neste sentido, vale tomar como hipóteses, a Psicologia, atenta às diversas formas de "alívio" do sofrimento psíquico, poderia levar em consideração as contribuições advindas de manifestações de religiosidade africana?

Como poderiam estas práticas contribuir para a constituição de uma Psicologia Afrocentrada no Brasil voltada ao sofrimento psíquico da população de africanos e afro-descendentes? Objetivo geral, investigar como manifestações de religiosidade africana se constitui enquanto trato do sofrimento psíquico. Objetivos específicos, investigar qual a relação existente entre religiosidade africana e o trato do sofrimento psíquico; analisar como as manifestações de religiosidade africana em suas práticas contribuem com a elaboração de uma psicologia afrocentrada no Brasil; identificar as contribuições da oralidade para a ma- 
nutenção, transmissão e resistência da memória e a da identidade do povo de matriz afrocentrada.

Justificam-se esses objetivos por entender a necessidade de levar ao universo acadêmico uma reflexão sobre o tema acima mencionado e suas contribuições para práticas psicológicas afrocentradas, devido ao preconceito, discriminação sócio-econômico-étnicocultural-religiosa, embranquecimento, demandas de sofrimento, perpetuados ao longo dos tempos a africanos e afrodescendentes, devido à escravidão, até os dias atuais. 0 método aplicado é de revisão de literatura.

\section{RELIGIOSIDADE AFRICANA NO TRATO DO SO- FRIMENTO PSÍQUICO}

Simmel (1909 APUD DALGALARRONDO, 2008, p. 23) e Bellot (1962 APUD DALGALARRONDO, 2008, p. 23) são estudiosos que comungam sobre religiosidade enquanto fator determinante na vida de indivíduos, tomando como sentimento religioso original e distinto em cada ser humano.

No artigo, Encenando o invisível: a construção da pessoa em ritos mediúnicos e performaces de auto-ajuda, o autor coloca "o sagrado como um campo privilegiado de figuração e produção de experiências de identidade e alteridade" (STOLL, 2009, p. 13), privilegiando a existência do ser humano na configuração de sua identidade e de suas raízes culturais.

Religiosidade, nesta produção significa sentimento religioso promotor de ligação e religação do ser humano à parte e expressão Divina, no Universo; manifestação da alma humana, exercício da fé. Pereira (2003, p. 33) traz fé enquanto "manifestação psicológica do sentimento de religação, que emana do inconsciente" do sujeito, constituída da subjetividade do mesmo, numa conexão, com o sagrado manifesto. "A fé em ação é sentir o poder da força" da espiritualidade "no ato de crer".
Considerando o acima mencionado, é de fundamental importância nos debruçarmos sobre os estudos, registros e pesquisas afrocentradas, sendo portanto, possível pensar Religiosidade Africana a partir do antigo termo SakhuSheti,

Extraído do MeduNetcher [A Escrita de Deus] Sakhu significa a compreensão, o iluminador, o olho e a alma do ser, aquilo que inspira. Shetientrar profundamente no assunto; estudar a fundo; pesquisar nos livros mágicos; penetrar profundamente. É necessário uma compreensão plena da pessoa africana. (NOBLES, 2009, p. 279-280).

A religiosidade, enquanto sentimento manifesto de fé, contém traços de identidade e de memória, numa relação de conexão, inserção e integração com o sagrado, vinculada ou não a uma religião. No livro, As Águas de Oxalá, o autor conceitua religião, na perspectiva dos integrantes do candomblé Yorubá, como conjunto de crenças, obrigações e práticas, onde se reconhece o mundo divino, cumprem-se preceitos e pedem-se favores. Da religião parte um complexo ritualístico de valores éticos e morais que visam aproximação como o sagrado, concebido no sujeito, na dimensão de sua fé (BENISTE, 2005, p. 32).

No artigo, Psicopatologia e religiosidade no lugar do outro: uma escuta levinasiana, os autores revelam que:

A escuta clínica em psicoterapia e os atendimentos psiquiátricos e psicológicos no Brasil encontram-se povoados de 'Joãos'. Trata-se de pessoas que, ao mesmo tempo em que buscam ajuda científica - psicológica e médica - buscam também outras formas de ajuda, em especial a ajuda espiritual. Explicações científicas se entrelaçam com formulações místicas. Religiosidade e psicopatologia se superpõem de uma maneira tal, que fica difícil identificar os limites entre uma e outra, onde termina a experiência psicopatológica e tem início a religiosidade e vice-versa. (FREIRE e MOREIRA, 2003, p. 93).

\section{EXÍLIO:LUGARDESUBMISSÃOERESISTÊNCIA.}

No Brasil, os africanos trazidos como escravos eram obrigados a receber o batismo, tinham os mem- 
bros de sua linhagem separados para a quebra da unidade da família (BENISTE, 2005, p. 27) e submetidos às determinações de dominação e controle impostas pelo homem branco, experienciando um violento silenciamento de todos os seus referenciais quanto a vínculos sociais e culturais.

Assim, no Brasil, os cultos funcionaram como elemento de afirmação do negro, que ao sentir-se despedaçado por não ter o direito de cultuar seus próprios deuses criou para isso acontecer, inúmeros subterfúgios (JOAQUIM, 2001, p. 31). Os escravos, em contato com a religião dominante, eram forçados a ser batizados na igreja católica. Em sua grande maioria, simulavam submissão ou até mesmo conversão, visando sobrevivência, aceitação, reconhecimento e, até mesmo, poder ou mesmo, prestígio.

Os negros encontraram um canal de voz e resistência, por meio da prática de sua religiosidade e espiritualidade, expressando a identidade e memória de seu povo, por meio da história oral, contadas em coletividade, pelos mais velhos. Anciãos conscientes de seu papel de transmissão da tradição e cultura, numa atitude de resistência e manutenção de seu povo.

O exercício da fé e da religiosidade ancestral, imbricados com a religião eurocêntrica dominante, constituiu o que conhecemos como Candomblé, em seus mais diversos formatos. Um fazer coletivo, de estrutura familiar, em sua origem, matriarcal, tornou-se espaço de acolhimento para os negros despatriados e seus descendentes, forma de referência e manutenção de vínculo com o continente africano.

No processo sócio-histórico de escravização do povo africano, a prática religiosa de fé por meio do culto aos orixás, produziu um contato com suas raízes e tradições culturais, amenizando a dor e o sofrimento psíquico do exílio devido ao tráfico de escravos; num exercício de fé, resistência e reorganização da vida individual e coletiva, caminho a ser percorrido na reconstituição da identidade deste povo e seus afrodescendentes.
A fé enquanto fenômeno psicológico traz que é sempre uma manifestação natural de todo ser racional, que, no entanto, transcende à razão (PEREIRA, 2003, p. 19). Os autores, no artigo $O$ olhar dos psiquiatras brasileiros sobre os fenômenos de transe $e$ possessão, informam que:

Nina Rodrigues, ao colocar como animismo as manifestações de religiosidade e fé dos negros escravos, tidos como irracionais e selvagens; apenas aptos ao trabalho servil, considerava o valor psicológico positivo desses fenômenos, pelos efeitos catárticos e ritualísticos, controlados pelo pai do terreiro e grupo religioso. Para ele, as manifestações satisfariam as necessidades emocionais "primitivas dos seus adeptos e não deveriam ser reprimidas", nem pela polícia, nem pela sociedade em geral. (ALMEIDA e DALGALARRONDO, 2007, p. 36).

O sofrimento psíquico referido neste trabalho é o do povo transplantado, sufocado em suas paixões. Sujeito acometido de sofrimento físico e psíquico decorrente da exacerbação de suas paixões, oriundas da exploração humana, dominadas ou não, por outros sujeitos, pela dominação, pelo preconceito e descriminação de toda ordem.

\section{UM OLHAR SOBRE AFRICANIDADE PARA UMA PSICOLOGIA AFRICANA}

As práticas de culto necessitam ser compreendidas, não como problemas ou manifestações destes, mas, antes, como soluções encontradas pelo sujeito para expressão de seu pathos enquanto paixão elaborada e transformada, por meio de sua religiosidade e exercício de fé.

Na configuração de uma cultura, "religião é objeto privilegiado na interlocução com a saúde e os transtornos mentais" (DALGALARRONDO, 2008, p. 15), por conseguinte, as manifestações de religiosidade contribuem para o trato de sofrimento psíquico e angústias de toda ordem, em inúmeros contextos. 
Ao tomarmos as manifestações de religiosidade de matriz africana como possível fonte de contribuições para elaboração de uma psicologia africana, vale considerar que essas manifestações de fé do povo negro diasporado, são fenômenos e, como tais, dialogando com Pereira (2003, p. 19) são fenômenos que podem interferir na psique, produzindo alterações nas funções psicológicas do sujeito que crê.

Compreendendo que a origem do sofrimento psíquico do povo negro diasporado decorre do processo de escravização dos mesmos, as sequelas promovidas em seus descendentes, até os dias atuais, tem sua diferenciação em relação às sequelas deixadas nos milhares de sujeitos no período do antes, durante e pós-conflitos mundiais. Assim, faz-se imprescindível a tarefa de elaboração de uma Psicologia Afrocentrada embasada nos aspectos bio-psico-sociais e culturais ligados à gênese do povo africano.

O psicólogo negro africanista norte americano, Nobles, membro de religião de matriz africana, em seu ensaio, SakhuSheti: retomando e reapropriando um foco psicológico afrocentrado, trata como:

\footnotetext{
Fundamental a essa tarefa é criar e criticar um corpo de ideias, teorias e práticas destinado a favorecer a compreensão, a explicação e, quando necessário, a cura do ser, do vir-a-ser e da pertença africanos em todas as expressões históricas e desdobramentos contemporâneos. (NOBLES, 2009, p. 279).
}

Num processo de articulações em nosso país, em 1 de março de 2012, 0 Conselho Federal de Psicologia em suas atribuições, posicionou-se em nota pública, frente a especulações da mídia sobre a prática da Psicologia atravessada por preceitos religiosos:

Em resposta ao debate travado na mídia e nas redes sociais acerca da relação entre religiosidade e exercício profissional da(o) psicóloga(o), o Conselho Federal de Psicologia (CFP) esclarece o que segue.Não existe oposição entre Psicologia e religiosidade, pelo contrário, a Psicologia é uma ciência que reconhece que a religiosidade e a fé estão presentes na cultura e participam na constituição da dimensão subjetiva de cada um de nós. A relação dos indivíduos com o 'sagrado' pode ser analisada pela (o) psicóloga (o), nunca imposto por ela (e) às pessoas com os quais trabalha. (CONSELHO..., 2012, [on-line]).

Numa busca de fazer conhecedor aos afrodescendentes de suas verdadeiras origens, como resultado do ativismo de educadores negros e aliados, contamos com a Lei de Diretrizes e Bases da Educação Nacional contida na Lei $n^{0} 10.639 / 2003$, que determina a toda nossa sociedade assumir o legado africano como precondição para desenvolvimento e conhecimento enquanto humanidade, aos africanos e seus descendentes e ao Brasil como nação (NASCIMENTO, 2008, p. 17).

\section{METODOLOGIA}

Em Métodos e Técnicas de Pesquisa em Psicologia, Campos (2008, p. 54) nos orienta que estudos qualitativo-descritivos objetivam delinear e/ ou analisar as características para um determinado fenômeno problematizado. Essa orientação cabe a esta pesquisa. Este trabalho resulta de revisão sistemática sobre Religiosidade africana e sofrimento psíquico por meio de pesquisas realizadas em BVS PSI e BIREME, Bases de Dados: LILACS, MEDLINE, COCHRANE E SCIELO.

0 trabalho contou com duas fases: primeira, definição dos descritores, busca dos mesmos nas bases mencionadas. Segunda, processo seletivo de refinamento: idioma, o português; linha temporal para literaturas primárias permitido anteceder a 2007 e, a partir de 2007 até o momento atual, para secundárias.

Os textos e obras pesquisadas e selecionadas foram elencados sob critérios, a seguir: número de fontes; aspectos introdutórios (referências, questão de estudo - objeto - bases teóricas - Objetivos); metodologia (número de participantes, tipo de pesquisa, linha teórica, tempo de pesquisa, local da pesquisa, instrumentos) e resultados (análises, propostas, conclusões). 
A busca segue na perspectiva sócio-histórica, numa dimensão interpretativa, lógico-dedutiva, entre a antropologia, a filosofia, a psicologia social, psicologia sócio-histórica e a psicologia africana. Por ser uma produção descritiva, analítica e crítica à luz de conhecimentos sobre Psicologia, segue num contexto afro-brasileiro afrocentrado e, ao final, serão apresentadas considerações finais, embasadas nas leituras realizadas para essa revisão, visando atender aos objetivos mencionados.

\section{CONSIDERAÇ̃ES CONCLUSIVAS}

Sem pretensão de esgotar o tema, consideremos as hipóteses anteriormente mencionadas, os estudos dos trabalhos de autores selecionados e mais os respaldos legais elencados nesse trabalho, torna-se possível tomarmos como relevantes as manifestações de religiosidades de matriz africanas como lugar de acolhimento, agregação e organização dos diasporados africanos em sofrimento devido à escravidão e pós-abolição, por meio de suas práticas culturais e de fé, como contribuições para elaboração de uma Psicologia Afrocentrada no Brasil.

Essas formas de agregação e acolhimento produziram formas de resistência, organização da psique humana, resgate da identidade e amparo de grupos inteiros no resgate de sua identidade, memória e autoestima, profundamente abaladas e fragilizadas pelas ações de tortura e morte, dentro como fora do sistema da escravidão.

Vale ressaltar que, por ainda termos uma sociedade marcada pela discriminação, preconceito, racismo, dentre outros fatores homogeneizantes e elitistas para com uma população, em sua maioria negra afrodescendente, imersa em conhecimentos ancestrais sincretizados devido ao processo colonizador; o povo negro que fez parte da realização socioeconômica identitária de nossa sociedade e cultura necessita ter sua autoestima e identidade reconhecidas por si mesmo e pelo social que o integra, assim reconhecido como tal, de modo determinante de afirmação e seu lugar no contexto sociocultural.

As manifestações de religiosidade de matriz africana promoveram uma profunda organização e articulação cultural entre africanos e europeus. Por meio da agregação de indivíduos, provenientes de várias regiões de África, as manifestações formaram uma estrutura circular de acolhimento, visando ordenação e sobrevivência frente às mazelas da escravidão e pós-abolição, dando assim amparo aos sujeitos e possível promoção de redução de seus sofrimentos, por meio de seus saberes, fazeres, costumes e tradições ancestrais, desconhecidas pelo colonizador, mas profundamente enraizadas na memória, na cultura e no espírito do povo africano.

\section{REFERÊNCIAS}

BENISTE, José. As águas de Oxalá: (àwonomiÓsalá). 3.ed. Rio de Janeiro: Bertrand Brasil, 2005.

CAMPOS, Luis Fernando de Lara. Métodos e técnicas de pesquisa em psicologia. 4.ed. Campinas, SP: Alínea, 2008.

CASTILLO, E. Lisa. Entre a oralidade e a escrita. A etnografia nos candomblés da Bahia. Salvador: EDUFBA, 2010.

CONSELHO fEDERAL DE PSICOLOGIA. Nota Pública do CFP de esclarecimento à sociedade e às(o) psicólogas(o) sobre Psicologia e religiosidade no exercício profissional. 28/2/2012. Disponível em: <http://site.cfp.org.br/>. Acesso em: 15 mar. 2015

\section{DALGALARRONDO, P. Religião, psicopatologia e} saúde mental. Porto Alegre: Artmed, 2008.

FREIRE J. C.; MOREIRA Virgínia. Psicopatologia e religiosidade no lugar do outro: uma escuta 
levinasiana. Departamento de Psicologia -

Universidade Federal de Maringá. Psicol. Estud., v.8, n.2, Maringá july/dec. 2003; Relig. Soc., v.29, n.1, Rio de Janeiro, 2009.

JOAQUIM, Salete Maria. 0 papel da liderança religiosa feminina na construção da identidade negra. Rio de Janeiro: Pallas; São Paulo: Educ, 2001.

NASCIMENTO, Elisa Larkin (Org.). Afrocentricidade. Uma abordagem epistemológica inovadora. Coleção
Sankofa: matrizes africanas da cultura brasileira, n.4. São Paulo: Selo Negro, 2009.

PEREIRA, Josias. A fé como fenômeno psicológico. São Paulo: Escrituras, 2003.

STOLL, Sandra Jacqueline. Encenando o invisível: a construção da pessoa em ritos mediúnicos e performaces de auto-ajuda. Religião e Sociedade, v.29, n.1, Rio de Janeiro, 2009. 
Recebido em: 14 de Agosto de 2015

Avaliado em: 31 de Agosto de 2015

Aceito em: 31 de Agosto de 2015
1. Graduada em Letras Vernáculas pela Universidade Católica de Salvador (UCSAL); graduada em psicologia pela Faculdade Social da Bahia (FSBA); Especialização em psicopedagogia pela Universidade Contemporânea (UNC);Terapeuta Holística - Extensão pela Universidade do Estado da Bahia - (UNEB); Formação xamânica pela Fundação Terra Mirim. E-mail: maris23@ibest.com.br

2. Prof. Dra. do Programa Multidisciplinar de Pós-graduação em Cultura e Sociedade - Pós Cultura do Instituto de Humanidades Artes e Ciências Prof. Milton Santos-UFBA. Cantora com três álbuns lançados. Membro do Centro de Estudos Multidisciplinares em Cultura (Cult) da UFBA. Pós-doutorado em Sociologia na Universidade de Lisboa (UL); Doutora em Ciências Sociais (UFBA); Mestre em Artes Cênicas (UFBA). E-mail: marilda62@gmail.com 